\title{
2
}

\section{Work beyond age 65 in England and the United States}

David Lain

\subsection{Introduction}

During the $20^{\text {th }}$ century the age of 65 became institutionalized as the most common male state pension age across OECD countries (Ebbinghaus 2006). Women in countries such as the UK received earlier state pensions, and men on average also retired below age 65 for much of the post-war period (Ebbinghaus 2006). However, pressures to work past 65 are now growing considerably. In the UK and USA state pension ages are rising to 67 for both men and women by 2027 , reaching age $69 / 70$ over time if they are linked to life expectancy projections as currently proposed (Béland and Waddan 2012; The Guardian 2013b). Cash benefits for retirees below age 65 will decline, and opportunities for early exit via salary-related occupational pensions have diminished considerably (Friedberg and Webb 2005; Clark 2006).

Given the rising need to work, this chapter considers prospects for employment beyond age 65 in the USA and England, the largest country of the UK. Both the UK and USA are typically labelled liberal residual welfare states (following Esping-Andersen 1990) with relatively unregulated competitive liberal market economies (after Hall and Soskice 2001). However, as we discuss in the first section, US policy has done more historically to promote employment beyond age 65 ; this includes disallowing most employers from setting mandatory retirement ages in 1986. UK policy is, however, catching up with that of the USA. In 2011 the 'default retirement age' of 65 was abolished, greatly reducing the ability of organizations to retire off people automatically at this age. Following a policy discussion, the main part of this chapter assesses the factors influencing employment at age 65 to 74 using the English Longitudinal Study of Ageing and the US Health and Retirement Study. The final section discusses the findings of the chapter, namely that socio-economic characteristics built up over the life course will constrain employment past 65 for significant numbers. We therefore need positive policies that promote equitable and realistic employment/retirement outcomes for older people. 


\subsection{The institutional context and increasing pressures to work past 65}

Until the early 2000s the principles underpinning US retirement policy arguably differed in emphasis from those of the UK (Lain 2011). The USA has promoted 'self-reliance' amongst older people to a greater degree: access to benefits for those with low pensions was limited, but protection from forced retirement via age discrimination legislation was strong. In the UK a more 'paternalistic' policy-logic was in operation in the past: older people were viewed as a more vulnerable group, with a more extensive safety net for poorer pensioners but few employment rights (Lain 2011). To summarize these differences, we might draw on Leisering's (2003: 222) assessment that “Americans view retirement as a matter of civil rights while Europeans view it as a matter of social and political rights". Americans have been more opposed to legal mandatory retirement ages than their British counterparts in the past (Hayes and Vandenheuvel 1994), while Britons have been more likely than Americans to say it is the government's responsibility to ensure "a decent standard of living for the old" (Hicks 2001: 7). This greater UK concern for poorer older people has been reflected in the means-tested safety net made available, rather than through generous social insurance pensions.

Before we examine retirement policy it is important to acknowledge that a US policy focus on selfreliance actually affected older cohorts throughout their life courses. Leisering (2003: 206) argues that in the USA "Government activities are more designed to secure equal opportunities [for example through education]... than to promote security across the lifecourse". The USA was a laggard in developing social insurance but was a leader in providing education as a means of promoting selfreliance (Lindert 2004). Older Americans consequently continue to have higher levels of education than their UK counterparts (OECD 2004: 58), placing them in a potentially stronger position with regard to obtaining work (Kanabar 2012).

\subsubsection{Policies affecting older people up to the early $2000 \mathrm{~s}$}

UK state pension provision developed out of concern for poverty in older age identified in surveys (Rimlinger 1971: 229; Williamson and Pampel 1993: 43); it was initially flat-rate and intended to provide a subsistence income, rather than replicating market positions. The original state pension was set too low to do this, however, and a supplementary second pension was introduced in the 1970s; this typically provided very modest pensions to those without occupational pensions. While a significant 
proportion had occupational pensions, in 2005 around a third of pensioner households received income-tested benefits in the form of social assistance-based Pension Credit, Housing Benefit or benefits to cover local taxes (DWP 2007). These benefits would be largely lost as a result of working, but employment of this group was not expected (Lain 2011).

In line with the general thrust of promoting self-reliance, the US Social Security pension was designed to be "consistent with the dominant values of self-help and rewards from individual effort" (Rimlinger 1971: 229). Like occupational pensions of the time Social Security was earnings related to reward previous work (Williamson and Pampel 1993). Over time the formula became redistributive, replacing lower levels of earnings at higher replacement rates, and providing supplements for partners (usually wives) with low pensions in their own right. However, low earnings resulted in a low pension, even when a person had a full contribution record. Someone on half average earnings throughout their working life would receive a pension worth 25 per cent of average earnings in the mid-2000s (Lain et al. 2013). In the UK the pension level for those on half average earnings would be comparable to the USA (Lain et al. 2013), but there would also be a greater safety net of means-tested benefits available. For those with low pension income in the USA, means-tested benefits were even less generous than in the UK and harder to get (Lain 2011). US housing benefits covered only part of the rent and were only received by a minority of eligible individuals, given budget constraints (Priemus et al. 2005; Lain 2011). US Supplemental Security Income (SSI) was more meagre than its UK equivalent, Pension Credit, and strict capital limits on eligibility restricted access (Lain 2011: 496). SSI became increasingly difficult to get over time (Elder and Powers 2006), given a lack of political will and public support to protect 'unearned' benefits and perceived abuse by non-contributing immigrants (Berkowitz and DeWitt 2013). This is in contrast to 'earned' Social Security, which enjoys much higher levels of public support (Harrington Meyer and Herd 2007).

In the context of a declining safety net, US employment rights for those over 65 were increased to encourage people to take financial responsibility for their retirement and its timing (Macnicol 2006). Mandatory retirement ages were outlawed in $1986,{ }^{1}$ following federal age discrimination legislation in 1967 and 1978, and state-level initiatives dating back as early as 1960 (Neumark and Stock 1999). The evidence suggests that "age discrimination legislation has succeeded at boosting the employment of older individuals through allowing them to remain in the workforce longer" (Adams 2004: 240). In the 
UK, on the other hand, people have had few employment rights beyond age 65 historically. In the recent past around half of individuals worked for organizations with mandatory retirement ages (Metcalf and Meadows 2006: 65). However, irrespective of mandatory retirement ages it appears that line managers were important in deciding who was allowed to work past age 65 (Metcalf and Meadows 2006: 75-6; Vickerstaff 2006).

\subsubsection{Reforms in the 1990s/2000s}

In both countries reforms will increase both the future need, and potential opportunities, to work past 65. State pension ages in both countries will rise to 67 by 2027 for men and women. In 2008 - the year this chapter examines - the state pension age in England was 65 for men and 60 for women. The increase to age 67 is therefore rapid compared with the USA, where 'normal' state pension age reached 66 by 2008. A US option of reduced pension at 62 will continue, but the reductions for early receipt will increase considerably as state pension ages rise (SSA 2014). The means-tested safety net for older people exiting employment before state pension age is also declining. The age at which those on low incomes can receive UK Pension Credit, 60 in 2008, is to rise to 67 in line with state pension increases. In the USA, access to means-tested Supplementary Security Income at 65 will decline further due to strict and unchanging asset requirements, leading Elder and Powers (2006) to dub it "the incredible shrinking program".

Other pension reforms encourage employment beyond 65. Limits on earnings that can be received whilst receiving a state pension have been lifted the UK (in 1989) and the USA (in 2000). Most people working past 65 in both countries receive their pension at the same time (Lain and Vickerstaff 2014). UK reforms in 2008 also make it easier for employers to allow older employees to continue working while receiving their occupational pension (Thurley 2011). The USA has alternatively mandated employers to continue contributing to an employee's pension if they work beyond normal pension age (Quadagno and Hardy 1991).

Wider pension changes also reduce opportunities to exit work before 65 . Historically, in both countries Defined Benefit (DB) salary-related occupational pensions were a common route to early retirement. However, these pensions have declined sharply, first in the USA (Friedberg and Webb 2005) and then in the UK (Pensions Commission 2004). US employers replaced DB pensions with 
Defined Contribution (DC) pensions which are effectively investment accounts that pay out a lump sum. In the UK, DC pensions did not increase sufficiently in number to replace closed DB pensions (Pensions Commission 2004). Starting in 2012 the UK government has therefore mandated employers without an approved occupational pension to automatically enrol employees into a DC scheme (unless the employee decides not to join). US and UK evidence suggests that people with DC pensions retire later on average than those with DB pensions (Friedberg and Webb, 2005; Arkani and Gough 2007; Banks et al. 2007). This reflects greater financial incentives to continue working and contributing to a DC pension (see Lain and Vickerstaff 2014) and the fact that these pensions typically provide less generous and secure retirement incomes. ${ }^{2}$

A final area of convergence between the two countries over time is in relation to employment rights. In 2006 UK age discrimination legislation was introduced for the first time, including the right to request continued employment beyond a 'default retirement age' of 65. In 2011 this 'default retirement age' was abolished, meaning that employers can no longer force retirement on the basis of age unless they can provide a legally defensible justification.

In summary, in both countries the needs and potential opportunities to work past 65 are increasing. However, it remains an open question as to whether employment will be realistic for many of those most in need of earnings; we turn to this issue now.

\subsection{Data}

We examine the factors influencing employment at ages 65 to 74 in 2008 , in order to assess the groups likely to remain in work in future. This is a useful time to compare the countries. US mandatory retirement had been abolished for decades by this point, but UK employers had a largely free hand in deciding whether someone could continue working beyond 65. In the UK women could access a state pension at 60 , but employers could not force them to retire until they reached 65. In the USA 'normal' state pension age reached 66 in 2008. However, most of those in the 65 to 74 age band in 2008 had been eligible for an unreduced pension when they were 65 .

Surveys with a high degree of comparability were analyzed: The English Longitudinal Study of Ageing (ELSA) and the US Health and Retirement Survey (HRS). We used comparable datafiles created by the RAND organization (see Phillips et al. 2012) alongside the original data. England has 
84 per cent of the UK population (ONS 2012), so the results should be broadly reflective of the UK as a whole. The analysis was conducted using STATA 13, and weights provided were used as advised by both surveys to increase the representativeness of the samples; it was particularly important to weight the HRS analysis because of its complex sample structure (Aneshensel 2013: 167-96). The unweighted sample of people aged 65 to 74 was 2,941 for England (including 405 workers) and 5,891 for the USA (1,668 workers). The non-regression results include 95 per cent confidence intervals. If the confidence intervals do not overlap we can say that the employment rate for one group (for example men) was different from that of another group (women) at the statistically significant level.

\subsection{Results}

We identify four important sets of factors influencing employment at 65:

- the need to work (including pensions, home ownership status and wealth);

- the capacity to work (including education and health);

- household factors (related to partnership status); and

- workplace factors.

We present analyses on each of these factors in turn, discussing the results in the context of the broader literature.

\subsubsection{Need factors}

As noted above, the lack of employment rights past age 65 in the UK has constrained the ability of many individuals to respond to financial needs or incentives by working. As table 2.1 shows, in 2008 , prior to the UK abolition of mandatory retirement ages, less than one sixth of the English worked at age 65 to 74 compared with just under a third of Americans. Women were less likely to work past 65 than men in both countries; apart from the generally lower labour market participation of women, this in part is likely to reflect the fact that some couples coincide their retirement and the female partner is likely to be younger (Pienta 2003; Loretto and Vickerstaff 2013). However, US women were more likely to work than English men, indicating the greater extent to which Americans worked.

Given the financial rationale for abolishing US mandatory retirement, this raises the question of whether the high US employment rate relates to Americans with financial needs or desires continuing 
in employment. People work for a range of financial and non-financial reasons, including an interest in the work itself or social reasons (Scherger et al. 2012; Parry and Taylor 2007). Nevertheless, financial considerations appear to be an important reason for working among many Americans. Analysis of a one-off self-completion questionnaire given to half the HRS sample reveals that 64.1 per cent of workers aged 65 to 74 said that they would ideally like to leave work now but they need the money (supplementary analysis, not shown). ${ }^{3}$ In England workers over pension age were asked why they worked; among 65 to 74 year olds 32.0 per cent stated they worked either to improve their finances or because they could not afford to retire. Although the questions were not asked identically, this does suggest that Americans were more likely than their English counterparts to be in employment for financial reasons. This may reflect a greater financial need to work in the USA compared with England to a degree, but it should be noted that average UK retirement incomes are relatively modest compared with the working-age incomes (Sefton et al. 2007). It is therefore likely Britons with modest retirement incomes were retiring with little sense there was an alternative (see Vickerstaff 2006). With the UK abolishing mandatory retirement we are likely to see a growth in financially motivated employment past 65 . UK survey evidence suggests that around three quarters ( 72 per cent) of older individuals expecting to work past state pension age give financial reasons (Smeaton et al. 2009: 80).

\section{[TABLE 2.1 here]}

While Americans are much more likely to say they were working for financial reasons, the relationship between financial resources and employment is complex. The descriptive analysis in table 2.1 suggests that in both countries those with the lowest resources appear to be least likely to work, which is consistent with previous research (Lain 2011; Haider and Loughran 2001; Crawford and Tetlow 2010: 21). If we look at household wealth (excluding housing and pensions) equivalized to the individual level, in both countries the poorest quartile was less likely to work than the quartiles above it. These differences were statistically significant with one exception (the higher rate of employment for the second lowest English quartile was not significant at the 5 per cent level). Americans in the lowest quartile were nevertheless more likely to be in employment than their counterparts in England 
relative to the USA may discourage employment to a degree (Lain 2011). It is likely, however, that in both countries lower levels of health and education limited employment prospects for poorer people (see regression analysis below). At the other end of the wealth spectrum, in both countries the largest estimated employment rate was for the highest quartile; this was significantly higher than the quartiles below it, with the exception of the third US wealth quartile and second English quartile.

These results only present a partial picture, however, as they exclude pensions and housing. Table 2.1 gives the proportions working among those with a private pension. This includes pensions the individual has received, or is entitled to receive in the future. Pensions may be from a current or former employer or held by the individual. For the USA we include Individual Retirement Accounts, because these are significant pension vehicles for the self-employed. Following the previous results we might expect the absence of a pension to reduce the likelihood of working, because it signifies wider disadvantage. In England, however, there was no significant difference in employment between those with and without pensions. Private pension coverage in England is, however, a weaker indicator of advantage and disadvantage than in the USA. Most people have at least a marginal pension from a previous employer, because of the ability to opt out of (some) state pension provision into private schemes. In the USA, on the other hand, having a pension significantly increased the likelihood of working: a third of those with a pension worked compared with a quarter of those without a pension.

This evidence suggesting employment is most concentrated amongst the advantaged should, however, be put in a broader context to help understand why so many Americans say they are working for financial reasons. First, it should be noted that employment was relatively high at all wealth quintiles compared with England, including the poorest. Second, as we will see below, US employment is associated with having a defined contribution pension; these typically provide less secure financial pathways out of work than defined benefit schemes (Lain and Vickerstaff 2014). Third, wealth and pensions ignore the importance of debts, in particular outstanding mortgages. Table 2.1 shows that in both countries having an outstanding mortgage significantly increased the likelihood of working, which is consistent with previous research (Mann 2011; Butrica and Karamcheva 2013; Smeaton and McKay 2003). In total, 41.6 per cent of those with an outstanding mortgage at age 65 to 74 were still working in the USA, compared with 27.5 per cent of outright homeowners. Likewise, the employment rates for England were 25.3 per cent for homebuyers compared with 13.2 per cent for 
outright homeowners. This is a particularly important issue in the USA because of a large increase in the proportion of people aged 62 upwards with mortgage debt (Butrica and Karamcheva 2013). As a result, 29 per cent of those aged 65 to 74 in the USA had an outstanding mortgage, rising to 38.9 per cent among workers (supplementary analysis not shown). In England the proportions with an outstanding mortgage were much lower (6.7 per cent overall versus 12.7 per cent among workers).

To summarize, there is convincing evidence the poorest groups were least likely to work. However, it is also evident that financial considerations were more generally an important influence on employment, particularly in the USA. In a context of greater financial uncertainty, people in both countries are increasingly having to decide whether to continue working for financial reasons. The question remains, however, whether they face barriers to employment.

\subsubsection{Capacity factors}

One set of explanations for lower employment among the poorest segment relates to what we call here 'capacity factors'; the evidence clearly demonstrates that better health and education increase the likelihood of employment. Health conditions are fairly common amongst older people even before they reach 65. In the UK around a quarter of people aged to 50 to 69 in 2008-09 had some kind of work disability limiting the kind or amount of work they could do (Crawford and Tetlow 2010: 32). The poorest are most likely to have a health condition (Banks et al. 2007) and least likely to work if they have one (Crawford and Tetlow 2010), presumably because of wider disadvantage and the lack of less physically strenuous jobs.

Table 2.1 presents two measures of health, both of which demonstrate its importance on employment. First, in both countries those rating their health as "good" were significantly more likely to be employed, although Americans with fair or poor health were more likely to work than their English counterparts. Second, table 2.1 shows the mean number of difficulties individuals report with Activities of Daily Living (ADLs). ADLs include up to eight activities involving lifting, climbing, stooping, walking, raising limbs, pushing, and rising from a chair (see Lain 2011). Table 2.1 shows that in both countries workers had significantly fewer ADL limitations than non-workers.

In addition to health, education is a capacity factor known to exert a strong influence on employment (Smeaton and McKay 2003; Lain 2011; Haider and Loughran 2001). Qualifications may 
facilitate more stable careers with fewer involuntary exits (Blekesaune et al. 2008). Qualifications may also make it easier for older people to move into new work if required or desired. US research suggests the likelihood of entering new 'bridge' employment, rather than retiring fully, increases with the number of years of education a person has received (Wang et al. 2008). Likewise, Kanabar (2012) found that in England the likelihood of returning to work after retirement was higher for the higher educated.

Education levels for England have been harmonized with the measure used in the HRS in table 2.1 (Phillips et al. 2012). The bottom two categories relate to whether or not the individual has attained "high school" secondary level qualifications. "Some college" refers to individuals with qualifications between high school and higher education; this includes, for example, English A levels. Finally, "college +" includes undergraduate higher education degrees and above. In both countries having a higher education degree roughly doubles the likelihood of working relative to someone with below secondary qualifications. Americans with degrees were nevertheless around twice as likely to work as their English counterparts, with 43.2 per cent in work compared with 22 per cent in England.

[Figure 2.1 here]

It is clear that highly educated Americans were able to take advantage of opportunities to work past age 65 in large numbers. Furthermore, relative to England, these highly educated Americans were a comparatively large group. Figure 2.1 presents educational profiles for each country. Just over fifth of Americans of this cohort had a college degree, around twice that of England. At the other end of the qualification spectrum, less than one fifth of Americans had qualifications below secondary level compared with more than half in England (see also OECD 2004). Purely because of their size the modal group of "workers" in England - around a third in total - were those with below secondary qualifications. Low qualifications place particular constraints on older people working up to and beyond age 65 in the UK, given the need to compete for jobs with more highly qualified younger people (Kanabar 2012). Qualification levels have risen markedly in the UK in more recent cohorts, but have not caught up with the USA so the problem will remain (OECD 2004). 


\subsubsection{Household factors}

While individual factors are important, people often make decisions about work and retirement from within a household and family context (Loretto and Vickerstaff 2013). To explore this, Table 2.2 breaks down employment rates by partnership status for men and women. "Partnered" individuals are married or are part of a cohabiting couple; employment rates are given for those with and without a working partner. For a small third category we do not know the employment status of their partner; in both survey samples around a hundred individuals aged 65 to 74 were in this category (118 in England and 117 in the USA). We also include "single" people in the table; these are individuals without a partner due to divorce, separation, widowhood, or never having been married.

[Table 2.2 here]

Table 2.2 shows that in both countries people in couples were much more likely to be employed if they had a working partner. For those with a working partner employment rates were similarly high in the USA (44.1 per cent) and England (38.7 per cent). The proportions employed with a non-working partner were much lower: 26.1 per cent in the USA and 9.2 per cent in England. This big disparity in employment between those with and without working partners in England suggests that household influences are particularly strong in the UK. In England 46.7 per cent of men with a working partner were employed, compared with only 12.5 per cent of those with a partner not in employment.

Likewise, 28.5 per cent of women with a working partner were employed, compared with only 5.7 per cent of those with an inactive partner. The corresponding differences for US men and women were important, but less pronounced (see table 2.2). It should also be noted that in the USA employment was high among those with non-responding partners, although it unclear why from this analysis.

Moving on to single people, it is evident that employment rates did not vary dramatically on the basis of gender in either country. In the USA, 31.2 per cent of single men worked compared with 26.4 percent of single women. Likewise, in England 11.4 per cent of single men worked compared with 10.6 per cent of single women. In both countries single women were more likely to work than women with a non-working partner, but less likely to work than partnered women with an employed partner. 
Unfortunately due to sample sizes it is not possible to disaggregate employment levels of single women by whether they were divorced, separated, widowed or never-married. However, we would expect different employment rates across these groups. For example, previous research suggests that in both countries employment is relatively high for older female divorcees, presumably for financial and social reasons (Smeaton and McKay 2003; Pleau 2010). The results suggest partnership status is an important employment influence, although more research is needed on single people (Lain 2011).

The final section of table 2.2 provides data on ethnicity and age. In neither country were there statistically significant employment differences between ethnic groups, although this may be due to the broad categories used. Table 2.2 also shows that workers were on average aged 68 , compared with 69 for non-workers.

\subsubsection{Logistic regression of capacity and need factors}

The above discussion suggests that capacity factors such as education and health are important influences on employment past age 65. However, it is important to disentangle these relationships; highly educated individuals may, for example, only be more likely to work because of better health. We therefore present a logistic regression analysis on whether an individual aged 65 to 74 is working (a score of one) or inactive (score of zero). This allows us to see the way in which one variable (education, for example) increases or decreases the likelihood of employment, controlling for the effects of other variables in the regression. The independent variables are those from the previous analysis.

To make the results more meaningful we present average adjusted predictions (AAPs), as per the suggestion of Williams (2012). These show the likelihood of working of an 'average' person within a particular category (for example, men). 'Average' equates to the average effect across all observed cases when only changing the variable in question. For example, the column titled AAPs in table 2.3 shows that the 'average' man in the USA has a likelihood of working of 36.1 per cent (an AAP of 0.361), compared with 26.3 per cent for the 'average' women (an AAP of 0.263). This controls for the effects of other independent variables in the regression that might account for higher employment among men than women. 
[TABLE 2.3 here]

In addition to AAPs we present average marginal effects (AMEs). These represent how much the likelihood of working differs between a particular group (for example, women) and the reference category group (men). Table 2.3 shows that the AME for American women is -0.098 , which indicates that their likelihood of working was 9.8 percentage points lower than that of American men. This AME is the difference between the AAP for women and the AAP for men $(-0.097=0.263-0.361)$; whether or not the difference is statistically significant is shown. In this case, American women were significantly less likely to work than men, taking into account other variables in the regression. Similarly, the AME for English women shows that they had a reduced likelihood of working of around 5 percentage points (an AME of -0.048).

Starting with capacity factors, qualifications were associated with an increased employment likelihood in both countries, after taking into account the effects of other variables. The US AAPs show that over a third of those with college and above education were predicted to be employed compared with a quarter of those with below high school qualifications. The corresponding AMEs suggest that somebody in the USA with below secondary high school qualifications was 8.4 percentage points less likely to work than somebody with a college degree; this difference was significant. Indeed, the college-educated in the USA were significantly more likely to work than all of the qualification groups below them. In England, after other factors taken into account, 16.3 per cent of college-educated people worked, compared with 11.1 per cent of those with below high school qualifications. The corresponding AME results show that this low educated group was 5.2 percentage points less likely to work than their college-educated counterparts, a result that was significant. For the middle three qualification groups, the AME signs were in the expected negative direction, which suggests a lower likelihood of working than for the highly educated. However, these results were not significant, perhaps partly due to smaller sample sizes. Nevertheless, in both countries having higher qualifications increased the likelihood of working significantly relative to the low educated, after taking into account other factors such as health.

As expected, poor health significantly reduced the likelihood of working in both countries. Somebody with good health was 13.8 percentage points more likely to be in employment in the USA 
than someone with fair or poor health; the corresponding figure for England was 7.1 percentage points. Limitations to activities of daily living were included in the regression and had the expected significant effects, but these results cannot be presented as AAPs because they are continuous variables.

Moving on to need factors, in both countries those in lower wealth quartiles were no longer less likely to work once we take into account capacity, household and other factors. This result is different from Lain (2011), who discovered that those with the lowest wealth in England were still significantly less likely to work after controlling for health, education and age in 2002. This may reflect the different time period examined. However, this chapter also uses a different measure of wealth (excluding housing) and is able to control for a broader range of factors that might explain lower rates of employment among those with the least wealth. In any case, the regression analysis suggests that lower levels of employment among the least wealthy can be attributed, in part, to lower work-capacity and household factors.

The only aspect of relative advantage increasing the likelihood of working is having a private pension in the USA (albeit at the weak ten per cent level). This may be due to the unmeasured relative advantage of those with pensions increasing their likelihood of working (for example, related to job quality). Alternatively, people might be working as a response to financial incentives within DC pensions to increase their retirement incomes. We examine the influence of pension type on employment later.

The final measure related to need in table 2.3 is housing status. In both countries people buying their house were significantly more likely to still be working than those owning the house outright. "Buyers" had an increased likelihood of working of 8.8 percentage points in the USA and 6.7 percentage points in England. In the USA, but not England, being a renter also increased the likelihood of working (albeit at the ten per cent level), taking into account other factors. Overall, then, need in the form of outstanding housing costs remained an important influence on employment in the regression.

The final segment of table 2.3 confirms the importance of the household for employment. People in couples with a working partner had an increased likelihood of working of 11.8 percentage points in the USA and 20.7 percentage points in England; the employment status of the partner was therefore 
particularly important in England as we saw earlier. In the US people with a non-responding partner were also significantly more likely to work than those reporting that their partner was not employed. Taking into account other variables in the regression, single people were more likely to work than married people with an active partner, presumably for a combination of reasons related to social contact and financial need.

In summary, the logistic regression analysis confirms the importance of capacity factors (health and education) and household factors on employment. Need factors in the form of outstanding mortgages also continued to be important. However, the lower likelihood of working for those in lowest wealth quartiles disappeared once we took into account other capacity and need factors. This supports previous research showing that low levels of health and education are impediments to working for the poorest (Lain 2011).

\subsubsection{Workplace factors}

A final set of factors examined relates to the workplace and the job held. This analysis focuses on individuals employed in 2002, drawing on work-related information from 2002 to examine how this influenced their employment in 2008. A slightly younger age cohort is examined, aged 62 to 70 in 2008 , to ensure everyone was below 65 in 2002. This results in a sample size of 2,579 in the USA (with 1,474 workers in 2008) and 1,142 in England (516 workers).

Table 2.4 first presents employment outcomes in 2008 descriptively, broken down by the type of pension held with their employer, if any, by workers in 2002 . This could be a salary-related defined benefit (DB) pension, a defined contribution (DC) pension providing a pension lump sum, or a hybrid scheme. Hybrid schemes are similar to DC schemes in that they pay a lump sum upon retirement; however, like DB schemes they also retain some degree of predictability because the sponsor guarantees the interest rate (Johnson and Steuerle 2004). Only a minority of schemes are hybrids; these have been combined with DC schemes here because they provide similar incentives to continue working (Johnson and Steuerle 2004). Individuals could also be classed as being unsure of their pension type, or of having no pension at all with their current employer. The literature discussed above would suggest that people with defined benefit pensions were less likely to work past 65 ; table 2.4 provides some evidence for this. In both countries people with DB pensions in 2002 were around 10 
percentage points less likely to be working than those with DC or hybrid pensions. However, this difference is only significant at the 95 per cent level in the USA. For England, the wide confidence intervals indicate that the lack of significance may be due to the small sample size for those with private pensions.

[TABLE 2.4 here]

The second workplace factor, also related to need, is medical insurance in the USA. US employers have taken an important role in providing medical insurance due to the lack of a universal national health service of the kind found in England. Table 2.4, however, shows that being covered by employer-provided medical insurance in 2002 had no significant bivariate effect on the likelihood of working in 2008. This is partly due to the fact that over 65 s are covered by universal Medicare health insurance, which helps facilitate employment exit. However, Medicare insurance has had gaps in coverage (for example, in relation to medication costs), and as a result it is likely to have complex influences on employment undetected here (see Green 2006).

Other workplace factors in table 2.4 relate to the job itself. Individuals are categorized as being employees or self-employed in 2002; employees are disaggregated by workplace size. Previous research indicates that the majority of workers past 65 are employees in the UK and USA (Lain and Vickerstaff 2014). Nevertheless, in both countries workers over state pension age are more likely to be self-employed than younger workers (Karoly and Zissimopoulos 2004: 26; Smeaton and McKay 2003: 29). The self-employed may find it easier to continue working because they are less constrained by organizational policies and cannot be dismissed (Lain and Vickerstaff 2014); they are also less likely to have defined benefit pensions that encourage exit. Table 2.4 shows that in the USA self-employed individuals in 2002 were significantly more likely than employees to be still working in 2008.

In England employment estimates were highest for the self-employed and those in smaller workplaces (with 25 to 99 staff). The results lack statistical significance but are consistent with previous research (Smeaton and McKay 2003; Cebulla et al. 2007). Small employers are less likely to provide defined benefit pensions that encourage earlier retirement. They may also have found it easier to accommodate requests for continued employment and for reduced or flexible working hours 
(Cebulla et al. 2007). This is because they typically have fewer bureaucratic rules, including fixed retirement ages (Metcalf and Meadows 2006: 74). With the abolition of mandatory retirement for employers of all sizes in 2011 we may see a reduced concentration in small organizations. In the USA, where large employers have been forbidden from setting compulsory retirement ages, there is no detectable difference in employment on the basis of workplace size in 2002. As table 2.4 shows, mean working hours for those employed in 2002 and 2008 declined significantly, reflecting a preference among a significant number of older people for reduced hours (Lain and Vickerstaff 2014).

Finally, table 2.4 shows employment rates in 2008 for people in strenuous and non-strenuous jobs in 2002. An individual had a strenuous job if they rated it as "physical" or "heavy labour" in England, or if it required physical effort "all" or "most" of the time in the USA. Despite the different underlying questions, the proportions defined as having strenuous jobs were similarly high in both countries at just under a third (30.3 per cent in England and 30.1 per cent in the USA, not shown in table). Perhaps surprisingly, having a strenuous job in 2002 did not increase the likelihood of leaving work by 2008 in either country. This is probably because people of relatively older age in strenuous jobs in 2002 were already a self-selecting group with a high capacity to work; this is something for future research to examine further. Nevertheless, the physical nature of many jobs past 65 highlights the potential importance of capacity factors for realistically enabling employment in older age.

\subsection{Conclusions}

In future the need to work past 65 will increase considerably in the USA and UK. In this context, the UK abolished mandatory retirement in 2011. In terms of considering the possible consequences it may be insightful to look to the USA, where mandatory retirement ages were outlawed in 1986 to encourage those with modest pensions to continue working. American men and women in 2008 were more likely than those in England to work at all wealth, health and educational levels, and their employment was determined to a lesser degree by their partner's employment. While financial influences on employment were present in both countries, for example in relation to mortgage debt and pension type, these were stronger in the USA than in England as would be expected given the US policy legacy. 
Given the shifting policy context we might expect the UK to move closer to the USA in terms of witnessing a continued increase in employment past 65 for financial and non-financial reasons. However, close examination of the US results indicates that disadvantages are likely to constrain employment past 65 for many people. Capacity factors - low levels of health and education significantly reduce the likelihood of working in the USA and England. In both countries, the descriptive analysis shows that somebody with a degree was twice as likely to work as somebody with below secondary qualifications. However, older people in England are less highly educated than their counterparts in the USA; low qualifications will make it harder for many to remain in employment, particularly as they will be competing with more highly educated younger cohorts. The descriptive results also show that those in the lowest wealth quartile were least likely to remain in work in both countries, a reduced likelihood that was no longer there once capacity and other factors were controlled for in the regression analysis. This suggests that lower employment among the poorest is, in part, explained by disadvantages including low education and bad health built up earlier in the life course.

Further challenges to extending working life emerge when we recognize that employment behaviour is influenced by external factors. People in both countries make decisions about employment from within a particular domestic situation and are less likely to work if they have an inactive partner. This may be to coincide leisure activities or perhaps to care for a partner if they are ill (McGeary 2009). In addition, workplace factors are likely to influence whether people remain in employment, such as whether they are self-employed or an employee or perhaps have access to parttime work.

Capacity, household and workplace factors therefore influence and constrain prospects for work beyond age 65 . Abolishing mandatory retirement, although broadly positive, does little to help those with poor employment prospects, some of whom have paid pension contributions from an early age and will have to rely on diminishing state financial support. We therefore need policies that recognize long contribution periods and the fact that not everyone will realistically work up to and beyond 65 . 


\section{Notes}

1 The exceptions are where a fixed retirement age exists for safety reasons (Macnicol 2006: 237), or where the employer has fewer than 20 staff.

2 Employers contribute less on average to DC schemes (ONS 2013; Ghilarducci 2008). Furthermore, there has been a sharp decline in the regular income an annuity will buy using a DC pension pot (The Guardian 2013a). This has led the UK to join the USA in not requiring 'DC pensioners' to buy an annuity.

3 The weight provided for the self-completion survey was used.

\section{References}

Adams, S. J. (2004), 'Age discrimination legislation and the employment of older workers', Labour Economics, 11 (2), 219-41.

Aneshensel, C. (2013), Theory-based data analysis for the social sciences, Thousand Oaks CA: Sage Publications.

Arkani, S. and Gough, O. (2007), 'The impact of occupational pensions on retirement age', Journal of Social Policy, 36 (2), 297-318.

Banks, J., Emmerson, C. and Tetlow, G. (2007), Healthy retirement or unhealthy inactivity: How important are financial incentives in explaining retirement, London: Institute for Fiscal Studies, http://www.ifs.org.uk/publications/3972, date accessed 27 November 2014.

Béland, D. and Waddan, A. (2012), The politics of policy change: Welfare, medicare, and social security reform in the United States, Washington D.C.: Georgetown University Press.

Berkowitz, E. and DeWitt, L. (2013), The other welfare: Supplemental security income and U.S. social policy, New York: Cornell University Press.

Blekesaune, M., Bryan, M., Taylor, M. and Britain, G. (2008), Life-course events and later-life employment, DWP Research Report No. 502, Norwich: Department for Work and Pensions.

Butrica, B. A. and Karamcheva, N. S. (2013), Does household debt influence the labor supply and benefit claiming decisions of older Americans?, CRR WP 2013-22, Chestnut Hill, MA: Center for Retirement Research at Boston College. 
Cebulla, A., Butt, S. and Lyon, N. (2007), 'Working beyond the state pension age in the United Kingdom: The role of working time flexibility and the effects on the home', Ageing and Society, $27(6), 849-68$.

Clark, G. L. (2006), 'The UK occupational pension system in crisis', in: H. Pemberton, P. Thane and N. Whiteside (eds.), Britain's pensions crisis: History and policy, Oxford: Oxford University Press, 145-68.

Crawford, R. and Tetlow, G. (2010), 'Employment, retirement and pensions', in: J. Banks, C. Lessof, J. Nazroo, N. Rogers, M. Stafford and A. Steptoe (eds.), Financial circumstances, health and well-being of the older population in England, London: Institute for Fiscal Studies.

DWP (2007), The pensioners' incomes series 2005/6 (revised), London: Department for Work and Pensions, http://webarchive.nationalarchives.gov.uk/20100407010852/http://dwp.gov.uk/docs/pens024220507.pdf, date accessed 12 March 2015.

Ebbinghaus, B. (2006), Reforming early retirement in Europe, Japan and the USA, Oxford: Oxford University Press.

Elder, T. E. and Powers, E. T. (2006), 'The incredible shrinking program', Research on Aging, 28 (3), $341-58$

Esping-Andersen, G. (1990), The three worlds of welfare capitalism, Princeton: Princeton University Press.

Friedberg, L. and Webb, A. (2005), 'Retirement and the evolution of pension structure', Journal of Human Resources, 40 (2), 281-308.

Ghilarducci, T. (2008), When I'm sixty-four: The plot against pensions and the plan to save them, Princeton: Princeton University Press.

Green, C. A. (2006), 'The unexpected impact of health on the labor supply of the oldest Americans', Journal of Labor Research, 27 (3), 361-79.

The Guardian (2013a), Annuity rates rise but reprieve may be short-lived, by J. Pappworth, 16 March 2013, http://www.theguardian.com/money/2013/mar/16/annuity-rates-rise-reprieve-short-lived, date accessed 20 January 2015. 
The Guardian (2013b), A pension age of 70? That's what is in store for overburdened generation $Y$, by T. Clark, 5 December 2013, http://www.theguardian.com/society/2013/dec/05/pension-age-70in-store-generation-y, date accessed 27 November 2014.

Haider, S. and Loughran, D. (2001), Elderly labor supply: Work or play?, CRR WP 2001-04, Boston: Center for Retirement Research at Boston College.

Hall, P. A. and Soskice, D. W. (eds.) (2001), Varieties of capitalism: The institutional foundations of comparative advantage, Oxford: Oxford University Press.

Harrington Meyer, M. and Herd, P. (2007), Market friendly or family friendly? The state and gender inequality in old age, New York: Russell Sage Foundation.

Hayes, B. C. and Vandenheuvel, A. (1994), 'Attitudes toward mandatory retirement - An international comparison', International Journal of Aging \& Human Development, 39 (3), 209-31.

Hicks, P. (2001), Public support for retirement income reform, OECD Labour Market and Social Policy Occasional Papers No. 55, Paris: OECD.

Johnson, R. W. and Steuerle, E. (2004), 'Promoting work at older ages: The role of hybrid pension plans in an aging population', Journal of Pension Economics and Finance, 3 (3), 315-37.

Kanabar, R. (2012), Unretirement in England: An empirical perspective, Discussion Paper Series No. 12/31, York: Department of Economics and Related Studies, University of York.

Karoly, L. A. and Zissimopoulos, J. (2004), 'Self-employment among older US workers', Monthly Labor Review, 127 (7), 24-47.

Lain, D. (2011), 'Helping the poorest help themselves? Encouraging employment past 65 in England and the USA', Journal of Social Policy, 40 (3), 493-512.

Lain, D., Vickerstaff, S. and Loretto, W. (2013), 'Reforming state pension provision in "liberal" anglo-saxon countries: Re-commodification, cost-containment or recalibration?', Social Policy and Society, 12 (1), 77-90.

Lain, D. and Vickerstaff, S. (2014), 'Working beyond retirement age: Lessons for policy', in S. Harper and K. Hamblin (eds.), International handbook on ageing and public policy, Cheltenham: Edward Elgar, 242-55.

Leisering, L. (2003), 'Government and the life course', in J. Mortimer and M. Shanahan (eds.), Handbook of the life course, New York: Kluwer Academic/Plenum, 205-25. 
Lindert, P. H. (2004), Growing public: Volume 1, the story: Social spending and economic growth since the eighteenth century, Cambridge: Cambridge University Press.

Loretto, W. and Vickerstaff, S. (2013), 'The domestic and gendered context for retirement', Human Relations, 66 (1), 65-86.

Macnicol, J. (2006), Age discrimination: An historical and contemporary analysis, Cambridge: Cambridge University Press.

Mann, A. (2011), 'The effect of late-life debt use on retirement decisions', Social Science Research, 40 (6), 1623-37.

McGeary, K. A. (2009), 'How do health shocks influence retirement decisions?', Review of Economics of the Household, 7 (3), 307-21.

Metcalf, H. and Meadows, P. (2006), Survey of employers' policies, practices and preferences relating to age, DWP Research Report No. 325, London: Department for Work and Pensions.

Neumark, D. and Stock, W. A. (1999), 'Age discrimination laws and labor market efficiency', Journal of Political Economy, 107 (5), 1081-125.

OECD (Organisation of Economic Co-operation and Development) (2004), Education at a glance 2004, Paris: OECD.

ONS (2012), 2011 Census: Population estimates for the United Kingdom, 27 March 2011, London:

Office for National Statistics, http://www.ons.gov.uk/ons/dcp171778_292378.pdf, date accessed 28 January 2014.

ONS (2013), Pension trends chapter 8: Pension contributions, 2013 edition, Newport: Office for National Statistics, http://www.ons.gov.uk/ons/dcp171766_310458.pdf, date accessed 27 November 2014.

Parry, J. and Taylor, R. (2007), 'Orientation, opportunity and autonomy: Why people work after state pension age in three areas of England', Ageing \& Society, 27 (4), 579-98.

Pensions Commission (2004), Pensions: Challenges and choices. The first report of the pensions commission, Norwich: T. S. Office.

Phillips, D., Chien, S., Moldoff, M., Lee, J. and Zamarro, G. (2012), RAND ELSA data documentation, version $b$, Bethesda, Maryland: Labor \& Population Program, National Institute on Aging/National Institutes of Health, 
http://doc.ukdataservice.ac.uk/doc/5050/mrdoc/pdf/5050_RAND_ELSA_B.pdf, date accessed 4 November 2014.

Pienta, A. M. (2003), 'Partners in marriage: An analysis of husbands' and wives' retirement behavior', Journal of Applied Gerontology, 22 (3), 340-58.

Pleau, R. L. (2010), 'Gender differences in postretirement employment', Research on Aging, 32 (3), 267-303.

Priemus, H., Kemp, P. A. and Varady, D. P. (2005), 'Housing vouchers in the United States, Great Britain, and the Netherlands: Current issues and future perspectives', Housing Policy Debate, $16(3-4), 575-609$.

Quadagno, J. S. and Hardy, M. (1991), 'Regulating retirement through the age-discrimination in employment act', Research on Aging, 13 (4), 470-5.

Rimlinger, G. V. (1971), Welfare policy and industrialization in Europe, America and Russia, New York: Wiley.

Scherger, S., Hagemann, S., Hokema, A. and Lux, T. (2012), Between privilege and burden: Work past retirement age in Germany and the UK, ZeS-Working Paper No. 4/2012, Bremen: Centre for Social Policy Research.

Sefton, T., Evandrou, M. and Falkingham, J. (2007), Mapping the incomes of older people in the UK, US and Germany, CRA Discussion Paper No. 0704, Southampton: Centre for Research on Ageing.

Smeaton, D. and McKay, S. (2003), Working after state pension age: Quantitative analysis, DWP Research Report No. 182, Leeds: Department for Work and Pensions.

Smeaton, D., Vegeris, S., Sahin-Dikmen, M. and Britain, G. (2009), Older workers: Employment preferences, barriers and solutions, Manchester: Equality and Human Rights Commission.

SSA (2014), Retirement planner: Benefits by year of birth, Baltimore: Social Security Administration, http://www.ssa.gov/retire2/agereduction.htm, date accessed 27 November 2014.

Thurley, D. (2011), Pension age: Occupational and personal pensions, Standard Note SN/05847, London: House of Commons Library.

Vickerstaff, S. (2006), '"I'd rather keep running to the end and then jump off the cliff." Retirement decisions: Who decides?', Journal of Social Policy, 35 (3), 455-72. 
Wang, M., Zhan, Y. J., Liu, S. Q. and Shultz, K. S. (2008), 'Antecedents of bridge employment: A longitudinal investigation', Journal of Applied Psychology, 93 (4), 818-30.

Williams, R. (2012), 'Using the margins command to estimate and interpret adjusted predictions and marginal effects', Stata Journal, 12 (2), 308-31.

Williamson, J. B. and Pampel, F. C. (1993), Old-age security in comparative perspective, Oxford: Oxford University Press. 